\title{
Automated Monitoring of the Establishment of the Adsorption Equilibrium: Adsorption of Polyethylene from 1,2,4-Trichlorobenzene onto a Zeolite at Temperature $140^{\circ} \mathrm{C}$
}

\author{
Tibor Macko, Robert Brüll, Christoph Brinkmann, and Harald Pasch \\ Department of Polymer Analysis, German Institute for Polymers, Schlossgartenstr. 6, 64289 Darmstadt, Germany \\ Correspondence should be addressed to Tibor Macko, tmacko@dki.tu-darmstadt.de \\ Received 8 May 2009; Accepted 4 June 2009 \\ Recommended by Peter Stockwell
}

The automated procedure for the monitoring of the adsorption process in the solute-sorbent-solvent system has been elaborated. It uses commercially available instrument CRYSTAF model 200. The application of CRYSTAF enabled monitoring of adsorption of linear polyethylene with weight average molar masses of 2, 14, and $53 \mathrm{~kg} / \mathrm{mol}$ from 1,2,4-trichlorobenzene onto zeolite SH-300 at temperature as high as $140^{\circ} \mathrm{C}$. It is the authors' understanding that this is the first demonstration of an adsorption isotherms for polyethylene. The measurement with the CRYSTAF instrument reduces manual manipulations with dangerous solvents at high temperature and enables automated long-time monitoring of the concentration of the solute in an adsorption system.

Copyright $\odot 2009$ Tibor Macko et al. This is an open access article distributed under the Creative Commons Attribution License, which permits unrestricted use, distribution, and reproduction in any medium, provided the original work is properly cited.

\section{Introduction}

Adsorption at liquid-solid interfaces plays an important role in both academia and industry. For example, adsorption is employed for the purification of liquids [1] in liquid chromatographic separations [2-4], in catalysis [5], and for solid phase extractions [6]. Adsorption is often characterized by an adsorption isotherm [7]. Several methods are known for obtaining the adsorption isotherms [4]. The classical approach of the construction of adsorption isotherms requires a long-time monitoring of the composition of a solution in contact with an adsorbent. In most cases, sampling and measurement are performed manually. In such a way, adsorption isotherms of alkanes [8-12], saccharides [13], phenol [14], polymers [7, 15-18], and peptides [19] in various solvent-sorbent systems have been determined.

We have selected polyethylene (PE), as adsorbate for several reasons. Polyethylene is the most industrially produced synthetic polymer (65 millions tons in the year 2004) [20]. Polyethylene differs from majority of other polymers in that it is composed only of atoms $\mathrm{C}$ and $\mathrm{H}$, without a polar group or double bond the chains, however, are strongly attracted to each other, that is, linear polyethylene might crystallize and belong to semicrystalline materials. As a result, linear polyethylene is not soluble at room temperature in any liquids. Linear PE is soluble after its melting in a limited number of liquids, which requires temperatures of $130-160^{\circ} \mathrm{C}$. High-temperature size exclusion chromatography using such liquids is routinely used for determination of molar mass distribution of polyethylene and other polyolefins [21]. Moreover, two methods, which are applied exclusively on polyolefins have been developed: temperature raising elution fractionation [22] and crystallization analysis fractionation [23]. Both techniques separate macromolecules on basis of their crystallinity in a temperature gradient.

We have recently observed the adsorption of polyethylene in chromatographic columns packed with zeolites from a series of mobile phases [24-26]. For example, polyethylene was adsorbed from 1,2,4-trichlorobenzene on zeolite SH-300 at a temperature of $140^{\circ} \mathrm{C}$ [24]. Although the adsorption of $\mathrm{n}$-alkanes (oligomers of PEs) from liquids onto zeolites is a known phenomenon $[8-12,27,28]$ the adsorption of $\mathrm{PE}$ on zeolites is a novel effect. PE is formed from the long chains, which in solutions form solvated shells of an irregular, approximately spherical shape. The ends of the chain are inside the shell. Pores of the zeolites have such small diameter, that macromolecular chain may penetrate into the pores only in an extended conformation (i.e., reptation) [26]. 


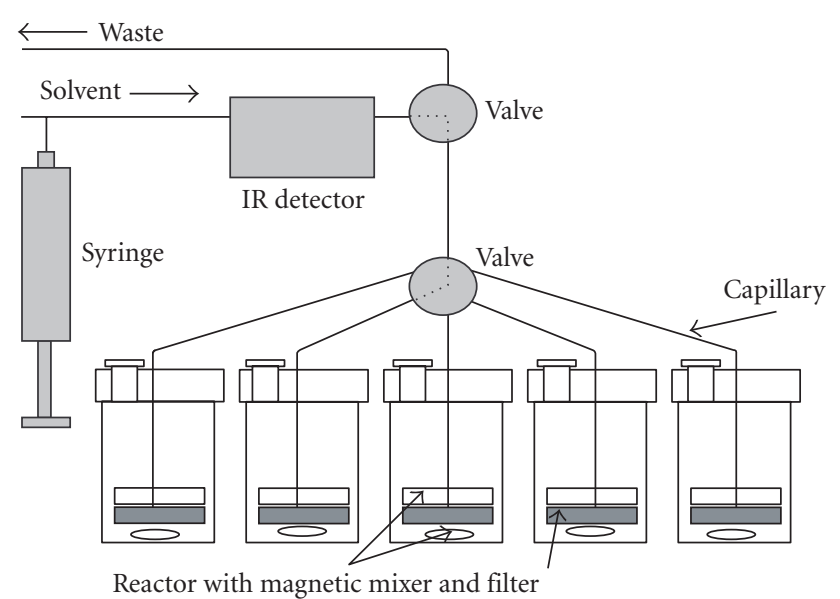

FIGURE 1: Scheme of the CRYSTAF apparatus.

NMR observations, however, are providing evidences about the inclusion of $\mathrm{PE}$ in the internal nanopores/channels of zeolites when they are adsorbed [29]. The penetration of chains into pores, at least partially, is probably a reason why the attempts to desorb the adsorbed PE have not been successful [30]. Namely, if pores are blocked by the adsorbed PE-chains, molecules of a solvent cannot penetrate into the pores and displace the polymer. Open issues include the depth of penetration of the polymer chains and extent of the adsorption.

Adsorption isotherms represent a key to better understanding of adsorption phenomena. According to the literature search an adsorption isotherm for polyethylene or other polyolefins has been never published. Because polyethylene is soluble only at temperatures $140-160^{\circ} \mathrm{C}$, the corresponding experiments have to be done at elevated temperatures. Manual manipulation with such hot, intensively evaporating and unhealthy solutions is difficult. For a quantitative evaluation of the polymer concentration following the adsorption, the hot polymer solution has to be separated from the sorbent.

With the aim to monitor the concentration changes connected with the adsorption of polyethylene from solutions, the CRYSTAF apparatus was utilized. Crystallization analysis fractionation (CRYSTAF) is a well-established analytical technique for the analysis of the chain branching distribution in semicrystalline polymers [23, 31-36]. The analytical procedure and the corresponding CRYSTAF apparatus were developed and commercialized by Monrabal [23]. The instrument enables a fully automated measurement of the dependence of the crystallization behavior of polymers as a function of temperature. An advantage of this technique is the automated sampling procedure (i.e., periodical monitoring of the concentration of polymers in several reactors), which reduces manual manipulations with samples and solvents to a minimum.

In this paper an automated monitoring of the process of adsorption in the adsorbate-solvent-sorbent system by the CRYSTAF apparatus is described. For the first time adsorption isotherms for polyethylene on the zeolite at a temperature of $140^{\circ} \mathrm{C}$ are determined.

\section{Experimental}

2.1. Polymer, Solvent, and Adsorbent. Linear polyethylene (PE) standards with average molar masses of $2.155 \mathrm{~kg} / \mathrm{mol}$ and $14 \mathrm{~kg} / \mathrm{mol}$ were obtained from Macherey-Nagel, Düren, Germany. Linear polyethylene (NBS standard 1475) with a weight average molar mass of $53.1 \mathrm{~kg} / \mathrm{mol}$ was obtained from National Bureau of Standards, Washington. 1,2,4trichlorobenzene ("for synthesis," TCB) was purchased from Merck, Darmstadt, Germany. Zeolite SH-300 with an Si/Al ratio of 150 and a particle size of approximately $10 \mu \mathrm{m}$ is a product of Alsi-Penta GmbH, Schwandorf, Germany with a surface area of $>400 \mathrm{~m}^{2} / \mathrm{g}$. The pore system of zeolite $\mathrm{SH}$ 300 contains linear channels with a free pore diameter of $0.56 \times 0.53 \mathrm{~nm}$, intersecting with sinusoidal channels, having a free diameter of $0.55 \times 0.51 \mathrm{~nm}$.

2.2. Description of CRYSTAF. A schematic of the CRYSTAF apparatus model 200 (Polymer Char S.A., Paterna, Spain) is shown in Figure 1. Five stainless steel reactors, with a volume of $50 \mathrm{~mL}$ each, are installed in an oven. Each reactor contains a filter and a magnetic stirrer. We have added a second magnetic stirrer to the reactors, which acts against sedimentation of the sorbent under the filter. The solvent is filled into the reactors with the aid of a motorized syringe. The composition of the solution in each reactor is monitored in predetermined intervals by an infrared detector (IR) at a wavelength of approximately $3.5 \mu \mathrm{m}$. The intensity of the IR signal is proportional to the concentration of $-\mathrm{CH}_{2}-$ groups. Reactors, valves, capillaries, and detector can be thermostated at a set temperature in the range of $20^{\circ} \mathrm{C}-180^{\circ} \mathrm{C}$. Parameters of measurement (temperature program, volumes of solvents, number of samplings, cleaning procedure) may be programmed by the software, which was delivered with the CRYSTAF apparatus.

2.3. Monitoring of the Adsorption Process by CRYSTAF. A small amount (between 5-30 mg) of polyethylene was placed manually in each reactor (Figure 1), and a preprogrammed amount $(30 \mathrm{~mL})$ of solvent was added by the motorized syringe (Figure 1). The samples of polymers were dissolved in the solvent with stirring for a set time (150 minutes at $160^{\circ} \mathrm{C}$ ). After the dissolution step, the temperature of the oven was decreased to $140^{\circ} \mathrm{C}$ and stabilized for 60 minutes. The IR response of the solution in each reactor was then measured three times.

Subsequently, $0.4 \mathrm{~g}$ of sorbent was added manually in small portions into each reactor and the reactors were closed. In the following 24 or 48 hours, 12 or 18 samples were taken from each reactor at regular intervals and their IR responses were recorded. For each sampling, $1.5 \mathrm{~mL}$ of solution was removed from the reactor and $1.1 \mathrm{~mL}$ of that was returned into the reactor after the measurement of the IR-response. The remainder, that is, $0.4 \mathrm{~mL}$ of the solution, was flushed into waste, when capillaries in the CRYSTAF were cleaned with the pure solvent. The final amount of the solution in each reactor was calculated after each concentration measurement by the CRYSTAF software. 


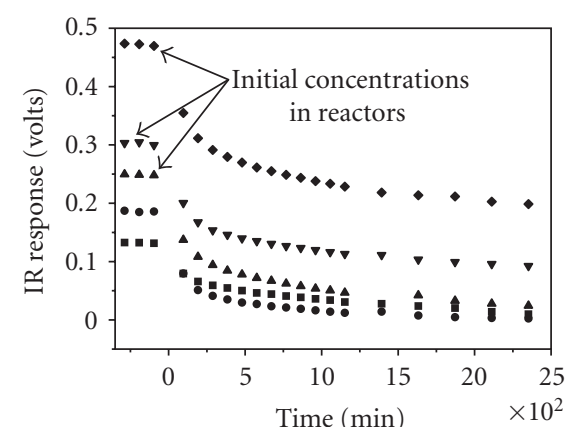

(a)

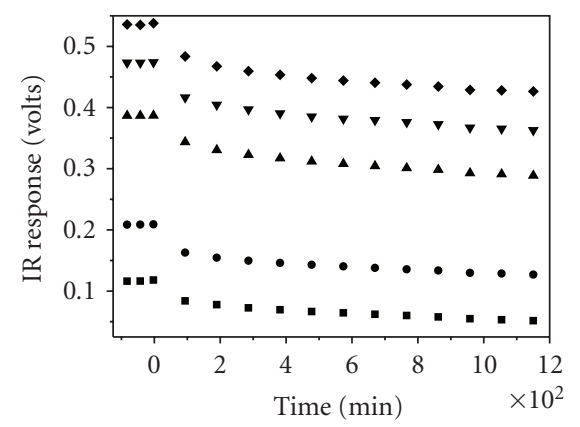

(b)

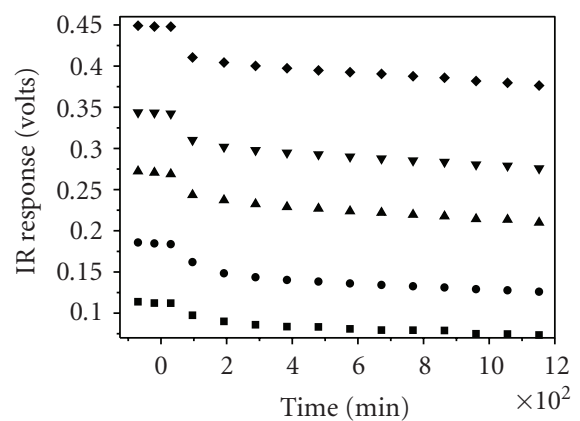

(c)

Figure 2: (a) Decrease of the IR detector response with time after the addition of the zeolite $\mathrm{SH}-300$ to solutions of polyethylene with an average molar mass of $2.155 \mathrm{~kg} / \mathrm{mol}$ in 1,2,4-trichlorobenzene. Temperature: $139-140^{\circ} \mathrm{C}$. Symbols: initial mass of polyethylene in the reactor: $-7.70 \mathrm{mg} ; \mathbf{\square}-11.20 \mathrm{mg} ; \boldsymbol{\Delta}-15.30 \mathrm{mg} ; \boldsymbol{\nabla}-$ $20.64 \mathrm{mg} ;-31.14 \mathrm{mg}$. (b) Decrease of the IR detector response with time after the addition of the zeolite $\mathrm{SH}-300$ to solutions of polyethylene with an average molar mass of $14 \mathrm{~kg} / \mathrm{mol}$ in $1,2,4-$ trichlorobenzene. Temperature: $139-140^{\circ} \mathrm{C}$. Symbols: initial mass of polyethylene in the reactor: $\square-4.8 \mathrm{mg} ;-10.5 \mathrm{mg} ; \boldsymbol{\Delta}-21.2 \mathrm{mg}$; $\nabla-26.1 \mathrm{mg} ;-30.39 \mathrm{mg}$. (c) Change of the response of the IR detector with time after the addition of zeolite $\mathrm{SH}-300$ to solutions of polyethylene with an average molar mass of $53.1 \mathrm{~kg} / \mathrm{mol}$ in 1,2,4-trichlorobenzene. Temperature: $139-140^{\circ} \mathrm{C}$. Symbols: initial mass of polyethylene in the reactor: $\square-6.44 \mathrm{mg}$; $\bullet-11.28 \mathrm{mg}$; $\boldsymbol{\Delta}-$ $16.64 \mathrm{mg} ; \boldsymbol{\nabla}-22.35 \mathrm{mg} ;-30.22 \mathrm{mg}$.

At the end of the measurements, the temperature in the oven was decreased to approximately $30^{\circ} \mathrm{C}$, the reactors were opened and the suspension of the sorbent was removed manually from the reactors. The reactors were washed with acetone. All the reactors were then cleaned automatically

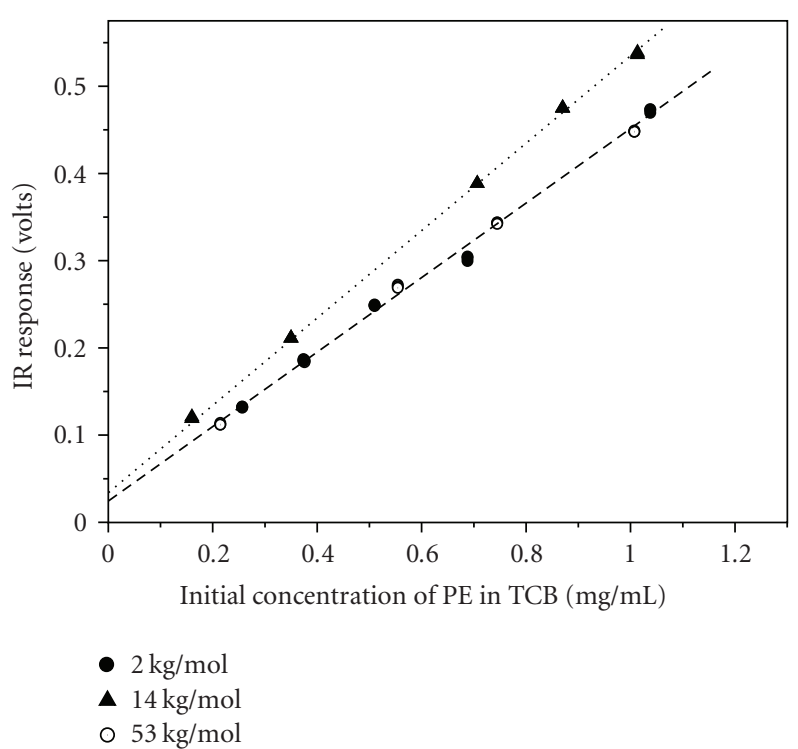

FIgure 3: Calibration of the IR response for polyethylene samples with different weight average molar masses in 1,2,4trichlorobenzene. Temperature: $139-140^{\circ} \mathrm{C}$.

with 1,2,4-trichlorobenzene at $160^{\circ} \mathrm{C}$ to remove residual polymer from filters and capillaries. Finally, the reactors were opened, dried, and thereby prepared for the following measurements.

The software delivered with CRYSTAF was used for the programming of the instrument and collection of experimental data. This software, however, was originally created for monitoring crystallization and not for monitoring adsorption. As a consequence, a constant temperature cannot be programmed, and a temperature gradient (at least $1^{\circ} \mathrm{C}$ per 24 hours) was required. Moreover, after 24 hours the measurement had to be terminated and a new measurement had to be started again.

\section{Results and Discussion}

3.1. Monitoring of Concentration and Evaluation of Data. The responses of the IR detector, which were obtained during the CRYSTAF experiments in the system polyethylenezeolite-1,2,4-trichlorobenzene are shown in Figures 2(a)2(c). The first three measured points correspond to the initial concentrations of the polymer in the reactors (i.e., before addition of the sorbent into the reactor). The dependence of the signals of the IR detector on the initial concentration of the solute enables to calibrate the IR detector. The IR response as a function of the solute concentration shows a linear correlation over the measured range (Figure 3 ). It is assumed that the slope of the lines in Figure 3 depends on batch-to-batch variations of solvent purity.

After the addition of the sorbent to the polymer solutions, the response of the IR detector, that is, the concentration of the polymer in solution, decreased (Figures $2(\mathrm{a})-2(\mathrm{c}))$. This is due to adsorption of the polymer on the zeolite SH-300 from 1,2,4-trichlorobenzene [24]. After 


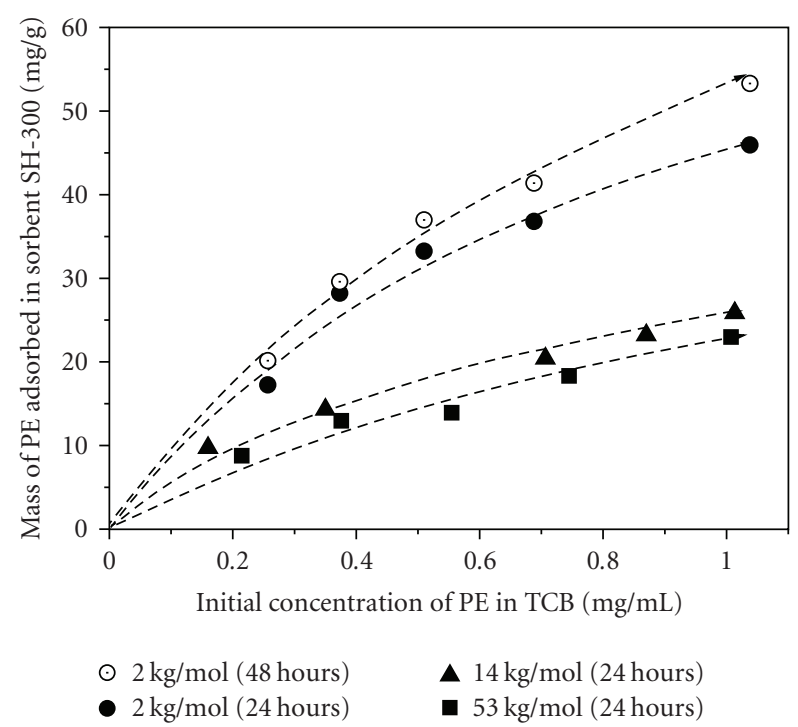

Figure 4: Plot of the adsorbed amount of polyethylene with different weight average molar masses per gram of zeolite $\mathrm{SH}-300$ against the initial concentration of polyethylene. Temperature: 139$140^{\circ} \mathrm{C}$. Polymers were 24 or 48 hours in contact with the sorbent.

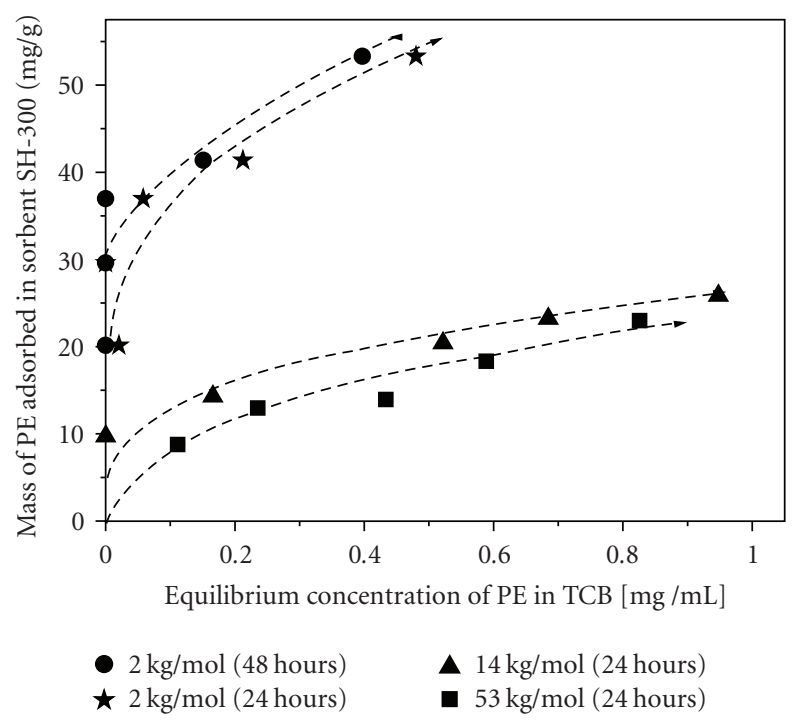

FIGURE 5: Adsorption isotherms for polyethylene with different weight average molar masses in 1,2,4-trichlorobenzene/zeolite SH300. Temperature: $139-140^{\circ} \mathrm{C}$. Polymers were 24 or 48 hours in contact with the sorbent.

48 hours there is only a very small change in concentration. Thus, the system should be close to the adsorption equilibrium. Unfortunately, due to limits in the CRYSTAF software, the measurements have to be interrupted after 24 hours. After the interruption, the temperature in the reactors and in the IR detector decreases. After restarting of the measurements, the interruption is not seen on the record only exceptionally (Figure 2(a)). For this reason, we have limited the monitoring of the adsorption process to 24 hours (Figures 2(b), 2(c)).
The amount of solute adsorbed on the sorbent in each reactor after 24 or 48 hours was calculated from the material balance. It was taken into account that the solute is not only adsorbed on the sorbent, but also a small amount of the solute goes into waste (volume $0.4 \mathrm{~mL}$ ) after each measurement of the IR response. The adsorbed amounts of polyethylene as a function of the initial polymer concentrations are shown in Figure 4. Dependences between the adsorbed amount of polyethylene and concentration of the polymer in the reactors after 24 and 48 hours are shown in Figure 5. The shape of the curves shows a sharp rise and a small rise. A longer monitoring ( $\sim 3$ days) of the polymer concentration in the reactors would likely be required for reaching of a plateau in these systems. Such prolongation of measurements will be possible after a modification of the CRYSTAF software. The presented data demonstrate that the changes of concentration, which are caused by the adsorption of polyethylene, are really possible to monitor continuously by the CRYSTAF instrument.

3.2. Comparison with Data from Literature. An adsorption isotherm for polyethylene in a solution has not, to the authors knowledge, been reported in the literature. On the other hand, the liquid-phase adsorption of $n$-alkanes, that is, oligomers of polyethylene, to zeolites, has been studied by several authors $[8-12,27,28]$ and in several cases also the adsorption isotherms were determined. For example, Alkandary et al. [8] found that at equilibrium, $93 \mathrm{mg}$ of $\mathrm{n}$ alkane eicosane $\left(\mathrm{C}_{20}\right)$ were adsorbed per 1 gram of Linde $5 \AA$ molecular sieve from isooctane at a temperature of $30^{\circ} \mathrm{C}$. $0.6031 \mathrm{mmol}(133 \mathrm{mg})$ of $\mathrm{n}$-pentadecane were adsorbed after 24 hours per 1 gram of zeolite NaZSM-5 from 1,3,5trimethylbenzene at temperature $50^{\circ} \mathrm{C}$ [11].

Gupta et al. [9] have reported a equilibrium loading of $141 \mathrm{mg}$ n-octane per $1 \mathrm{~g}$ of Linde $5 \AA$ molecular sieve from benzene at $30^{\circ} \mathrm{C} .107 \mathrm{mg}$ of $\mathrm{n}$-tetradecane per $1 \mathrm{~g}$ of zeolite Linde Type $5 \AA$ were adsorbed from 1,1,2,2tetrachloroethane at $90^{\circ} \mathrm{C}$ [12]. Although these values are larger compared to the one obtained for polyethylene (Figure 5), it has to be taken into account that adsorbates, adsorbent, solvent, and temperatures are not identical. An increase of temperature usually decreases the extent of adsorption, thus smaller values at $140^{\circ} \mathrm{C}$ may be expected. Really, polyethylene at $140^{\circ} \mathrm{C}$ is adsorbed in a smaller extent. Several groups $[9,11,12]$ have found that the equilibrium loadings decrease with increasing molecular weight for nalkanes (up to $\mathrm{C}_{50}$ ). This trend is also applicable to n-alkanes with larger molar masses, that is, polyethylene (Figure 5).

The experimental results presented here are in qualitative agreement with liquid chromatography measurements described herein [24]. Linear polyethylene standards with molar masses ranging from $1-260 \mathrm{~kg} / \mathrm{mol}$ were retained within the zeolite SH-300 column packing from 1,2,4trichlorobenzene at $140^{\circ} \mathrm{C}$ [24]. A comparison of peak areas indicated that the amount of the retained polymer decreased with an increase of its average molar mass. The same dependence is shown in Figure 5. 
Data about the adsorption of synthetic polymers on zeolites are very scarce in the literature. For example, using an MFI-type zeolite Buttersack et al. [15] have determined an adsorption equilibrium value of $82 \mathrm{mg}$ of polyethylene oxide (molar mass $43 \mathrm{~kg} / \mathrm{mol}$ ) per $1 \mathrm{~g}$ zeolite in water at a temperature $25^{\circ} \mathrm{C}$. The value determined at $140^{\circ} \mathrm{C}$ for polyethylene $53 \mathrm{~kg} / \mathrm{mol}$ in the present work $(22 \mathrm{mg} \mathrm{PE} / \mathrm{g} \mathrm{SH}$ 300 ) is smaller. In addition to the different temperature, polyethylene is, in comparison with polyethylene oxide, a nonpolar polymer, thus its ability for attractive interactions with a sorbent is quite limited. The adsorbed amount of polyethylene oxide decreased with the increase of the molar masses, that is, the same trend as with polyethylene (Figures 4 and 5) has been observed.

\section{Conclusion}

The experimental data needed for construction of the adsorption isoterms have been obtained by CRYSTAF. The CRYSTAF apparatus enables to monitor concentration of 5 solutions with different initial concentration of an adsorbate. This automated procedure is superior in comparison to the manual procedures as the manual manipulation with hot solutions is difficult. The first adsorption isotherms for polyethylene were constructed based on experimental data obtained by temperature $140^{\circ} \mathrm{C}$. According to a literature search, an adsorption isotherm for polyethylene has been newly published. Data about adsorption of polyethylene reflect interactions between this polymer and the surface of the sorbent. These attractive interactions are of interest not only for chromatographic separations but they also play a role in the catalytical cracking of polyethylene waste using zeolites [37].

Without modification the CRYSTAF apparatus may be applied for the measurement of adsorption data in the case that a low molecular substance or a polymer has an individual and pronounced IR response, such as polyethylene, that is, polyolefins. A solvent used has to exhibit a suitable IR window, where the polymer may be detected. For both alkanes and polyolefins, suitable solvents are, for example, tetrachloroethylene, $\alpha$-chloronaphthalene, o-dichlorobenzene, trichlorobenzene, or diphenylether [38]. Furthermore, the kinetics of the adsorption process can also be monitored. We expect, therefore, that the automated monitoring of the adsorption process has the potential to replace the manual procedures, which are up to present needed for obtaining of the experimental data. To be generally applicable for any type of adsorbed polymer or a low molecular substance in all common solvents, a universal detector, such as a refractometric index detector, would be needed.

Connecting the CRYSTAF with a UV detector or a diodearray detector could be also of interest in some cases.

The CRYSTAF apparatus, following the previously mentioned modifications, has the potential to be widely applicable instrument for the collection of the experimental data regarding adsorption of small molecules as well as macromolecules in various solvent-sorbent systems.

\section{Acknowledgments}

The authors would like to thank Mr. A. Ortin and Dr. B. Monrabal (Polymer Char S. A., Paterna, Spain) for the help and advices about the CRYSTAF. T. Macko thanks Dr. J. F. M. Denayer (Vrije Universiteit Brussels) for providing the zeolite sample.

\section{References}

[1] K. Valkó, Ed., Separation Methods in Drug Synthesis and Purification, Elsevier, Amsterdam, The Netherlands, 2000.

[2] P. Sadek, HPLC Guide, John Wiley \& Sons, New York, NY, USA, 2002.

[3] B. A. Bidlingmeyer, Ed., Preparative Liquid Chromatography, Elsevier, Amsterdam, The Netherlands, 1991.

[4] R. M. Nicoud and A. Seidel-Morgenstern, "Adsorption Isotherms: Experimental Determination and Application to Preparative Chromatography," Isolation \& Purification, vol. 2, pp. 165-200, 1996.

[5] M. Mengel, "Zeolithe," in Ullmanns Encyklopädie der Technischen Chemie, E. Bartholome, E. Biekert, H. Hellmann, H. Ley, W. M. Weigert, and E. Weise, Eds., vol. 24, pp. 575-578, Verlag Chemie, Weinheim, Germany, 1983.

[6] N. J. K. Simpson, Solid-Phase Extraction: Principles, Techniques, and Applications, Marcel Dekker, New York, NY, USA, 2000.

[7] Yu. S. Lipatov and L. M. Sergeeva, Adsorption of Polymers, John Wiley \& Sons, New York, NY, USA, 1983.

[8] J. A. M. Alkandary, R. Al-Ammery, and A. B. S. H. Salem, Separation Science and Technology, vol. 30, p. 3195, 1995.

[9] R. K. Gupta, D. Kunzru, and D. N. Saraf, "Liquid-phase adsorption of n-paraffins on molecular sieve," Journal of Chemical and Engineering Data, vol. 25, no. 1, pp. 14-16, 1980.

[10] A. K. Jain, R. V. Jasra, and S. G. T. Bhat, "Liquid-phase adsorption of olefin/paraffin mixtures on ion-exchanged $\mathrm{X}$ zeolite," Separation Science and Technology, vol. 25, no. 4, pp. 489-505, 1990.

[11] R. V. Jasra, N. V. Choudary, S. G. T. Bhat, A. G. Patel, and N. Subrahmanyam, "Liquid-phase sorption of higher alkanes and alkenes in zeolite NaZSM-5 at 10, 30, and $50^{\circ}$ C," Separation Science and Technology, vol. 32, no. 9, pp. 1571-1587, 1997.

[12] D. W. Sundstrom and F. G. Krautz, "Equilibrium adsorption of liquid phase normal paraffins on type 5A molecular sieves," Journal of Chemical and Engineering Data, vol. 13, no. 2, pp. 223-226, 1968.

[13] C. Buttersack, W. Wach, and K. Buchholz, "Specific adsorption of saccharides by dealuminated Y-zeolites," Journal of Physical Chemistry, vol. 97, no. 46, pp. 11861-11864, 1993.

[14] Yu. A. Eltekov and M. V. Kelzeva, "Adsorption of Phenol and Benzoic Acid from Water Solutions by Modified Adsorbents," Environment Protection Engineering, vol. 9, pp. 13-19, 1983.

[15] C. Buttersack, H. Rudolph, J. Mahrholz, and K. Buchholz, "High specific interaction of polymers with the pores of hydrophobic zeolites," Langmuir, vol. 12, no. 13, pp. 31013106, 1996.

[16] H. Grüll, R. Shaulitch, and R. Yerushalmi-Rozen, "Adsorption of PEO in highly confining porous glass," Macromolecules, vol. 34 , no. 23, pp. 8315-8320, 2001.

[17] G. J. Howard, C. C. Ma, and C. W. Yip, "Adsorption of oligomers," Polymer Communications, vol. 24, no. 6, pp. 182184, 1983. 
[18] M. Kawaguchi, M. Chikazawa, and A. Takahashi, "Displacement of polymers by displacers. 1. Polystyrene at the silica surface," Macromolecules, vol. 22, no. 5, pp. 2195-2199, 1989.

[19] T. Tsai, R. C. Mehta, and P. P. DeLuca, "Adsorption of peptides to poly(D,L-lactide-co-glycolide): 1 . Effect of physical factors on the adsorption," International Journal of Pharmaceutics, vol. 127, no. 1, pp. 31-42, 1996.

[20] H. Frey, F. Gröhn, and A. Kilbinger, "Macromolecular chemistry 2005," Nachrichten aus der Chemie, vol. 54, no. 3, pp. 292300, 2006 (German).

[21] S. Mori and H. G. Barth, Size Exclusion Chromatography, Springer, Berlin, Germany, 1999.

[22] L. Wild, T. R. Ryle, D. C. Knobeloch, and I. R. Peat, "Determination of branching distributions in polyethylene and ethylene copolymers," Journal of Polymer Science Part B, vol. 20, pp. 491-455, 1982.

[23] B. Monrabal, "Crystallization analysis fractionation: a new technique for the analysis of branching distribution in polyolefins," Journal of Applied Polymer Science, vol. 52, no. 4, pp. 491-499, 1994.

[24] T. Macko, H. Pasch, and J. F. Denayer, "Adsorption of polyethylene standards from decalin on liquid chromatography column packings," Journal of Chromatography A, vol. 1002, no. 1-2, pp. 55-62, 2003.

[25] T. Macko, J. F. Denayer, H. Pasch, and G. V. Baron, "Adsorption of polyethylene from thermodynamically good solvents on a zeolite stationery phase," Journal of Separation Science, vol. 26, no. 17, pp. 1569-1574, 2003.

[26] T. Macko, J. F. Denayer, H. Pasch, L. Pan, J. Li, and A. Raphael, "Adsorption of polypropylene and polyethylene on liquid chromatographic column packings," Chromatographia, vol. 59, no. 7-8, pp. 461-467, 2004.

[27] J. F. Denayer, A. Bouyermaouen, and G. V. Baron, "Adsorption of alkanes and other organic molecules in liquid phase and in the dense vapor phase: influence of polarity, zeolite topology, and external fluid density and pressure," Industrial and Engineering Chemistry Research, vol. 37, no. 9, pp. 36913698, 1998.

[28] S. Chempath, J. F. M. Denayer, K. M. A. De Meyer, G. V. Baron, and R. Q. Snurr, "Adsorption of liquid-phase alkane mixtures in silicalite: simulations and experiment," Langmuir, vol. 20, no. 1, pp. 150-156, 2004.

[29] X. Wang, C. C. Rusa, M. A. Hunt, A. E. Tonelli, T. Macko, and H. Pasch, "Adsorption of polyethylene and polypropylene by zeolites: inside or outside?" Macromolecules, vol. 38, no. 25, pp. 10341-10345, 2005.

[30] T. Macko, H. Pasch, and R. Brüll, "Selective removal of polyethylene or polypropylene from their blends based on difference in their adsorption behaviour," Journal of Chromatography A, vol. 1115, no. 1-2, pp. 81-87, 2006.

[31] L. J. D. Britto, J. B. P. Soares, A. Penlidis, and B. Monrabal, "Polyolefin analysis by single-step crystallization fractionation," Journal of Polymer Science Part B, vol. 37, no. 6, pp. 539552, 1999.

[32] R. Brüll, H. Pasch, H. G. Raubenheimer, R. Sanderson, A. J. van Reenen, and U. M. Wahner, "Investigation of the melting and crystallization behavior of random propene/ $\alpha$ olefin copolymers by DSC and CRYSTAF," Macromolecular Chemistry and Physics, vol. 202, no. 8, pp. 1281-1288, 2001.

[33] C. Gabriel and D. Lilge, "Comparison of different methods for the investigation of the short-chain branching distribution of LLDPE," Polymer, vol. 42, no. 1, pp. 297-303, 2001.

[34] H. Pasch, R. Brüll, U. Wahner, and B. Monrabal, "Analysis of polyolefin blends by crystallization analysis fractionation,"
Macromolecular Materials and Engineering, vol. 279, pp. 4651, 2000.

[35] P. Starck, P. Lehmus, and J. V. Seppala, "Thermal characterization of ethylene polymers prepared with metallocene catalysts," Polymer Engineering and Science, vol. 39, no. 8, pp. 1444-1455, 1999.

[36] Y.-D. Zhang, C.-J. Wu, and S.-N. Zhu, "Fractionation and characterization for a propylene-ethylene random copolymer," Polymer Journal, vol. 34, no. 9, pp. 700-708, 2002.

[37] H. H. Kung, "Role of adsorption in zeolite-catalyzed hydrocarbon cracking reaction," Research on Chemical Intermediates, vol. 26, no. 2, pp. 121-127, 2000.

[38] B. Monrabal, "Temperature Rising Elution Fractionation and Crystallization Analysis Fractionation," in Encyclopedia of Analytical Chemistry, R. A. Meyers, Ed., vol. 14, pp. 1-20, John Wiley \& Sons, New York, NY, USA, 2000. 


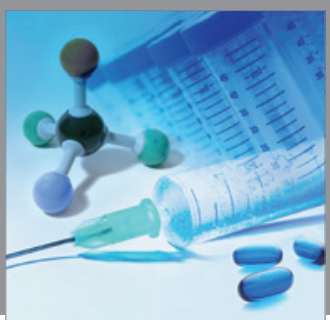

International Journal of

Medicinal Chemistry

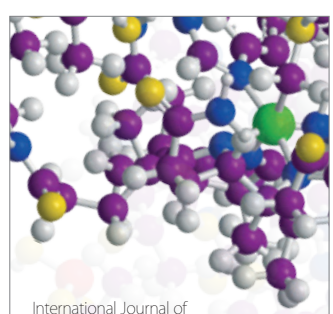

Carbohydrate Chemistry

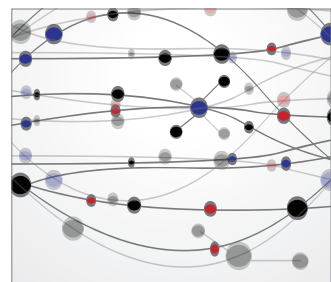

The Scientific World Journal
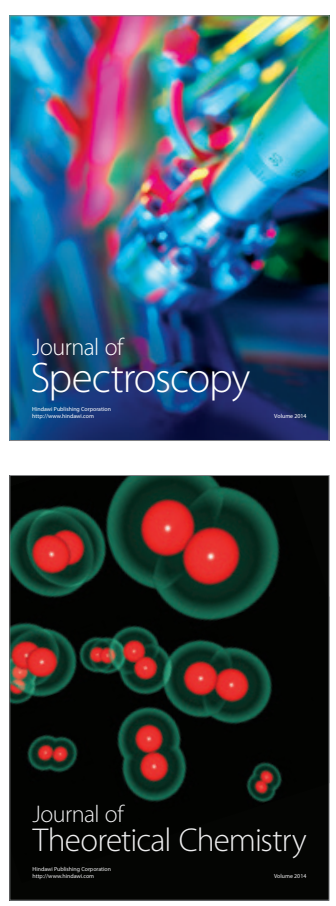
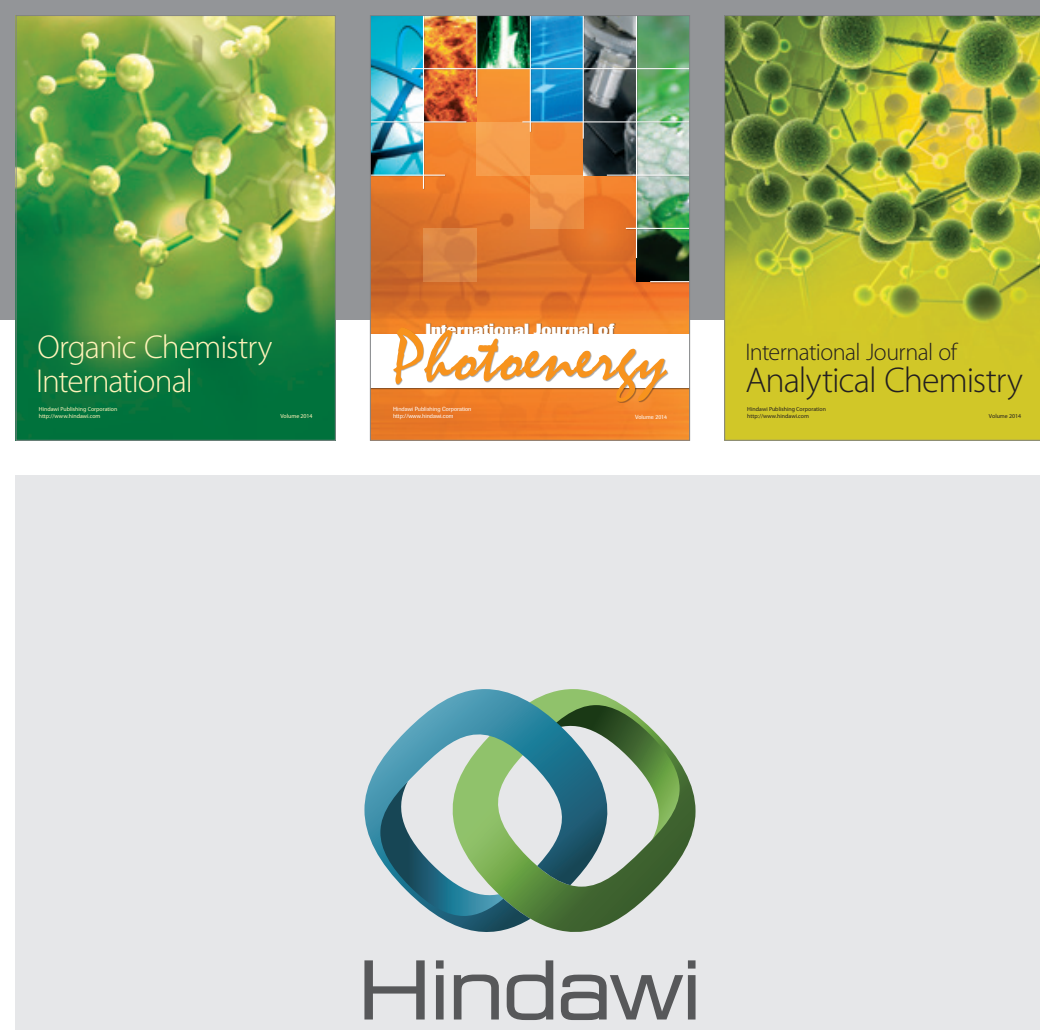

Submit your manuscripts at

http://www.hindawi.com
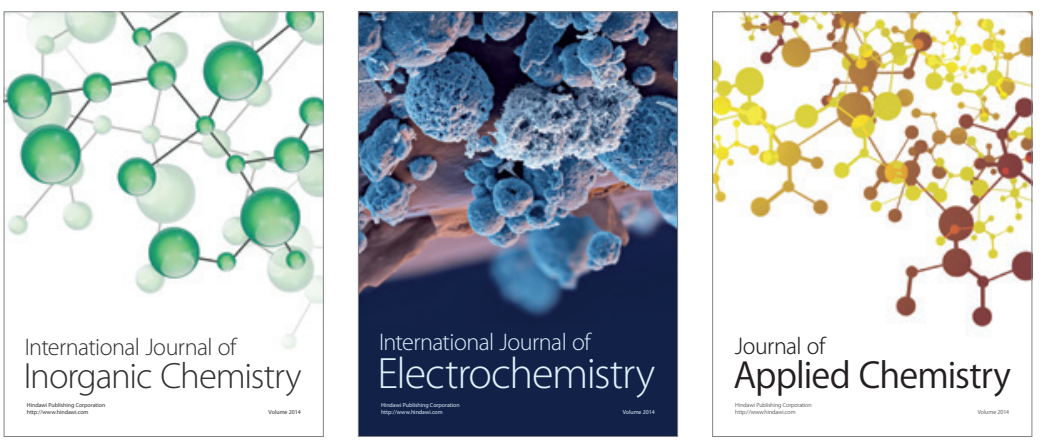

Journal of

Applied Chemistry
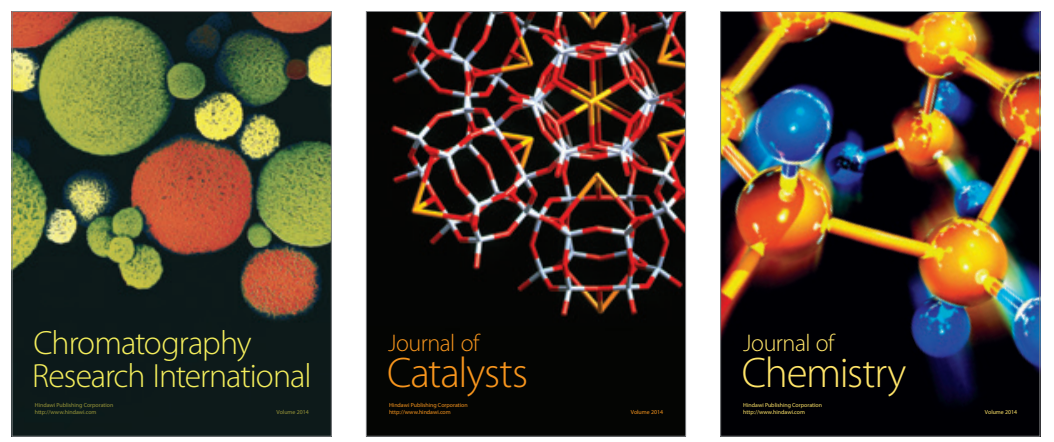
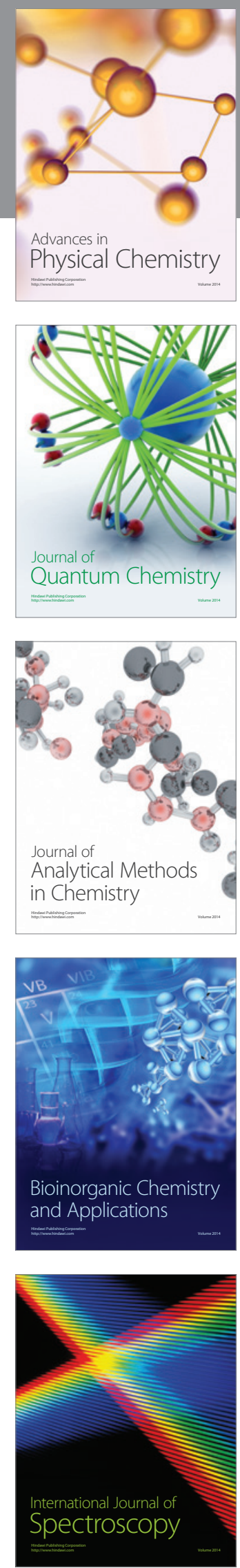